\title{
miR-133a-3p promotes apoptosis and induces cell cycle arrest by targeting CREB1 in retinoblastoma
}

Jianchang Li, Xiuming Liu, Wenqi Wang, Chaopeng Li

Department of Ophthalmology, The Affiliated Huaian No. 1 People's Hospital of Nanjing Medical University, Huai' an, Jiangsu, China

Submitted: 8 November 2018

Accepted: 25 December 2018

Arch Med Sci 2020; 16 (4): 941-956

DOI: https://doi.org/10.5114/aoms.2019.86901

Copyright $\odot 2019$ Termedia \& Banach

\section{Abstract}

Introduction: Retinoblastoma (RB) is a malignant tumor that is derived from photoreceptors. It is common in children under 3 years old with a family genetic predisposition. MicroRNA-133a-3p (miR-133a-3p) is one of the tumor-related miRNAs that interprets a critical function in the genesis and development of various tumors. This study investigated the effects and underlying mechanisms of miR-133a-3p in RB.

Material and methods: Quantitative reverse-transcription polymerase chain reaction ( $q R T-P C R$ ) analysis was used to assess the miR-133a-3p expression in RB tissues and a cell model. MTT assay, western blot, flow cytometry and luciferase reporter assay were performed to evaluate the effect of miR-133a$3 p$ on cell viability, apoptosis and the cell cycle. An RB xenograft model was established to assess the in vivo influence of miR-133a-3p on RB growth. Results: MiR-133a-3p level was reduced in RB tissues and the cell model $(p<0.01$ or $p<0.001)$. Addition of miR-133a-3p reduced cell viability, and increased apoptosis and cell cycle arrest $(p<0.001)$. Additionally, CREB 1 was identified to be the target of miR-133a-3p in RB cell lines $(p<0.001)$. Cell viability reduction, apoptosis and cell cycle arrest increases mediated by miR-133a-3p were attenuated by CREB1 overexpression $(p<0.001)$. MiR$133 a-3 p$ inhibited tumor growth of RB in vivo $(p<0.001)$.

Conclusions: Our results reveal that miR-133a-3p exhibits anti-cancer effects by targeting CREB 1 in RB. This study provides a new direction for effective targeted treatment of this disease.

Key words: miR-133a-3p, retinoblastoma, CREB1, apoptosis, cell cycle.

\section{Introduction}

Retinoblastoma (RB) is a type of malignant intraocular cancer with a relatively constant incidence in children globally [1]. The conventional treatments of RB are laser therapy and eyeball removal [2]. Chemoreduction, a new treatment of RB, aims to save children's lives by protecting their eyes and visual functions [3]. However, these treatments are prone to adverse effects on the children and have various limitations [4]. Therefore, it is imperative to explore new treatments for RB based on the intrinsic mechanism of tumorigenesis.

MicroRNAs (miRNAs) are usually composed of 22 nucleotides that are paired with complementary sequences of mRNA molecules [5]. They silence target genes by inhibiting mRNA translation or causing mRNA degradation [5]. Aberrant miRNA expression has been observed in various pathological conditions including solid tumors, indicating that

\author{
Corresponding author: \\ Xiuming Liu \\ Department \\ of Ophthalmology \\ the Affiliated Huai'an \\ No. 1 People's Hospital \\ of Nanjing Medical \\ University \\ 1 Huanghe Road West \\ Huaiyin District \\ Huai'an, Jiangsu \\ 223300, China \\ Phone: +86051780872120 \\ Fax: +86051780872120 \\ E-mail: LiuxiumingLLL@163. \\ com
}


miRNAs play an important part in tumor development [6-8]. Thus, miRNAs have been widely studied as potential biomarkers in various tumors, especially in RB $[5,9]$. Recently, it has been reported that miR-1792, miR-365b-3p and miR-101 regulate the formation, apoptosis and cell cycle of RB in vitro and in vivo [9-11]. As a common tumor-associated miRNA, miR-133a-3p is down-regulated in various cancers and acts as a tumor suppressor to prevent cancer development by regulating target genes in breast cancer, gastric cancer, pancreatic cancer and glioma [12-15]. However, the regulatory mechanism of miR-133a-3p in RB remains unclear. Cyclic AMP responsive element binding protein 1 (CREB1), encoded by the CREB gene, is a member of the leucine zipper transcription factor family [16]. It binds to CAMP response element (CRE) to stimulate transcriptional activation, which in turn regulates cell survival, proliferation and differentiation [17]. Numerous studies have shown an increased expression level of CREB1 in non-small cell lung cancer (NSCLC), melanoma and breast cancer compared to normal tissues [18-20], and down-regulation of CREB1 has been speculated to have anti-cancer potential [21]. However, the roles of CREB1 in RB have not been investigated. As an important proto-oncogene in the human body, CREB1 has been predicted to be the target of multiple miRNAs such as miR-27b, miR-34b, miR-181b, miR-182 and miR-200b [21, 22]. Interestingly, we identified CREB1 as a potential target of miR-133a-3p by bioinformatic analysis. Thus, in this study, we aimed to explore and validate the regulatory mechanisms of miR-133a$3 p$ and CREB1 in RB.

\section{Material and methods}

\section{Tissue collection and ethics statement}

Fresh RB tissue and adjacent non-tumor tissue samples were taken from patients diagnosed with RB according to clinical and pathological evidence, who underwent surgery in the Affiliated Huaian No. 1 People's Hospital of Nanjing Medical University from June 2016 to May 2018. Informed consent was obtained from all patients. All experimental procedures and protocols were approved by the Institutional Research Ethics Committee of the Affiliated Huaian No. 1 People's Hospital of Nanjing Medical University.

\section{Cell culture}

Human RB cell lines WERI-RB1 (HTB-169) and Y79 (HTB-18) were purchased from ATCC (Manassas, USA). SO-RB50 and normal retinal cells in children were obtained from the Cell Bank of the Chinese Academy of Sciences (Shanghai, China). Cells were maintained in Roswell Park Memorial Insti- tute (RPMI)-1640 medium (Thermo Fisher Scientific, Waltham, USA) supplemented with $10 \%$ fetal bovine serum (FBS) and $1 \%$ penicillin-streptomycin in a humidified incubator at $37^{\circ} \mathrm{C}$ with $5 \% \mathrm{CO}_{2}$. The culture medium was changed every 3 days.

\section{Cell transfection}

WERI-RB1 and Y79 were transfected with hsamiR-133a-3p mimics or hsa-miR-133a-3p inhibitor (Thermo Fisher Scientific, Waltham, USA), pBabe-puro-CREB1 or pLKO.1-CREB1 (BlueGene Biotech, Shanghai, China) or their corresponding negative control (NC). Briefly, cells were seeded at $2 \times 10^{5}$ cells/well in 6-well plates for $24 \mathrm{~h}$. Cell transfection was carried out using Lipofectamine 2000 (Invitrogen, Carlsbad, USA) according to the manufacturer's instructions. Six hours after transfection, cell media were replaced and cells were grown for an additional $48 \mathrm{~h}$ before carrying out downstream experiments.

\section{Cell viability assay}

Transfected cells were seeded at a density of $2 \times 10^{3}$ cells/well in 96-well plates. After 1, 2, 3, 4, 5 or 6 days of incubation, $11 \mu$ of MTT buffer ( $5 \mathrm{mg} / \mathrm{ml}$, Sigma-Aldrich, St. Louis, USA) was added to each well and further incubated for $4 \mathrm{~h}$. After the culture medium was removed, the precipitated formazan was dissolved in $150 \mu$ l of dimethyl sulfoxide (DMSO). The absorbance was measured at $490 \mathrm{~nm}$ (OD490) using a spectrophotometer (Thermo Fisher Scientific, Waltham, USA).

\section{Flow cytometry analysis}

Transfected cells were trypsinized with trypsin (Thermo Fisher Scientific, Waltham, USA) and fixed with $70 \%$ ethanol after washing in ice-cold phosphate buffer saline (PBS) at $4^{\circ} \mathrm{C}$ overnight. $\mathrm{PI}$ /RNase Staining Buffer (RUO; BD Biosciences, San Jose, USA) was used to stain treated cells in cell cycle assessment at room temperature for $20 \mathrm{~min}$. Binding buffer containing $5 \mu \mathrm{l}$ of propidium (PI) and $5 \mu \mathrm{l}$ of Annexin V-FITC (BD Biosciences, San Jose, USA) was used to assess the apoptosis rate. Cell cycle and apoptosis were observed using a FACSCalibur instrument (BD Biosciences, San Jose, USA) and analyzed using the FlowJo software (FlowJo LLC, Ashland, USA).

\section{Western blot analysis}

Transfected cells were lysed in ice-cold RIPA buffer with a protease inhibitor cocktail to extract the total proteins. The concentrations of protein were tested using the Pierce BCA protein assay kit (Thermo Fisher Scientific, Waltham, USA). Subsequently, samples containing equivalent 
protein were subjected to $10 \%$ sodium dodecyl sulfate-polyacrylamide gel electrophoresis (SDSPAGE) and electrophoretically transferred onto a polyvinylidene fluoride (PVDF) membrane (Millipore, Billerica, USA). Membranes were blocked with $5 \%(\mathrm{w} / \mathrm{v})$ skim milk in Tris buffered saline with Tween-20 (TBST) for $2 \mathrm{~h}$ at room temperature, and were incubated with primary antibodies: brain-derived neurotrophic factor (BDNF), cyclin B1, cyclin D1, glyceraldehyde-3-phosphate dehydrogenase (GAPDH), Bcl-2, Bax and cleaved caspase-3 (1 : 1000; Cell Signaling Technology, Danvers, USA), CREB1, pCREB1 and CAMP-responsive element modulator (CREM) (1 : 1000; Sigma-Aldrich, St. Louis, USA) at $4^{\circ} \mathrm{C}$ overnight. After washing in TBST, membranes were then incubated with goat-anti-rabbit IgG-horseradish peroxidase (HRP) secondary antibody (1 : 1000; Cell Signaling Technology, Danvers, USA) for $1 \mathrm{~h}$ at room temperature, and visualized via the Immobilon Western Chemiluminescent HRP Substrate (Millipore, Boston, USA). Densitometry analysis was performed using the Image J software (NIH Image, Bethesda, USA). GAPDH was used as the control [23].

\section{Quantitative reverse-transcription \\ polymerase chain reaction ( $\mathrm{RRT}-\mathrm{PCR}$ )}

Total RNA from human RB tissues, adjacent non-tumor tissues and RB cell lines were extracted by Trizol reagent (Invitrogen, Carlsbad, USA). cDNA was synthesized via One Step PrimeScript miRNA cDNA Synthesis Kit (TaKaRa, Tokyo, Japan), according to the manufacturer's protocols. qRTPCR was performed in an ABI7500 real-time PCR instrument (Applied Biosystems, Waltham, USA). All data were analyzed using the $2^{-\Delta \Delta c t}$ method [13]. MiR-133a-3p expression was normalized to U6, whereas CREB1 expression was normalized to GAPDH. Primer sequences were as follows: miR133a-3p 5'-UUU GGU CCC CUU CAA CCA GCU G-3' (forward), 5'-UAA ACC AAG GUA AAA UGG UCG A-3' (reverse); U6, 5'-CGC TTC GGC AGC ACA TAT AC-3' (forward), 5'-TTC ACG AAT TTG CGT GTC AT-3' (reverse); CREB1, 5'-CTT TTC TCC GGA ACA CAG ATT TC-3' (forward), 5'-GAT TTG CCA AGT GGG AGG GA-3' (reverse); GAPDH, 5'-CAC TCC TCC ACC TTT GA-3'(Forward); 5'-CCA CCA CCC TGT TGC TG-3' (reverse).

\section{Luciferase reporter assay}

CREB1 3'UTR wild-type (wt) or mutant (mut) was cloned into the pMIR-firefly luciferase reporters (Invitrogen, Carlsbad, USA), and named as pMIRCREB1 3'-UTR-WT or PGL3-CREB1 3'-UTR-MUT, respectively. PMIR-CREB1 3'-UTR-WT contained predicted miR-133a-3p binding sites, whereas
pGL3-CREB1 3'-UTR-MUT was constructed using the site-directed mutagenesis kit (TaKaRa, Tokyo, Japan) to encompass a mutated miR-133a-3p binding site. pRL-TK Renilla plasmids (Promega, Madison, USA) and miR-133a-3p mimics or NCs were co-transfected into cells using Lipofectamine 2000 (Invitrogen, Carlsbad, USA) according to the manufacturer's protocols. Dual Luciferase Assay System (Promega, Madison, USA) was used to measure luciferase activities $48 \mathrm{~h}$ after transfection according to the manufacturer's instructions.

\section{Tumor xenograft models}

Nude mice (Lab animal center of Air Force Military Medical University, Xian, China), 4-5 weeks old, weighing 60-80 g, were subcutaneously injected with Y79 cells $\left(2 \times 10^{7}\right.$ cells $\left./ \mathrm{ml}\right)$ transfected with miR-133a-3p mimics or its NC into the right eye anterior chamber. The eyes of mice were painted with $1 \%$ atropine eye ointment after injection. Tumor volumes were measured every 10 days from day 10 to day 40 . The tumor weight and volume were measured after mice were sacrificed.

\section{Statistical analysis}

All data were analyzed using the SPSS 21.0 software (IBM, Corporation, Armonk, USA) and are presented as mean \pm standard deviation (SD). Groups were compared using Student's $t$-test or one-way analysis of variance (ANOVA). The values of $p<0.05$ were considered statistically significant.

\section{Results}

miR-133a-3p expression is reduced in RB tissues and RB cell lines

To determine the expression profile of miR$133 a-3 p$ in RB, qRT-PCR was used to assess the expression levels of miR-133a-3p in RB tissues and cell lines. miR-133a-3p was found to be lower in RB tissues compared to non-tumor tissues $(p<0.0001)$ (Figure $1 \mathrm{~A})$. In addition, miR-133a-3p levels were reduced in $R B$ cell lines, including SO-RB50, WERI-RB1 and Y79 cells compared with the normal retinal cells $(p<0.01$ or $p<0.001)$ (Figure $1 \mathrm{~B}$ ). Hence, WERI-RB1 and $Y 79$ cells were selected for subsequent experiments.

\section{miR-133a-3p reduces cell viability, and} increases cell apoptosis and cell cycle arrest

After transfection of miR-133a-3p mimics or inhibitor in Y79 and WERI-RB1 cells, the transfection efficiencies were examined by qRT-PCR. The expression of miR-133a-3p was increased in the miR-133a-3p mimic group compared with the NC mimic group, whereas decreased miR-133a-3p 
A

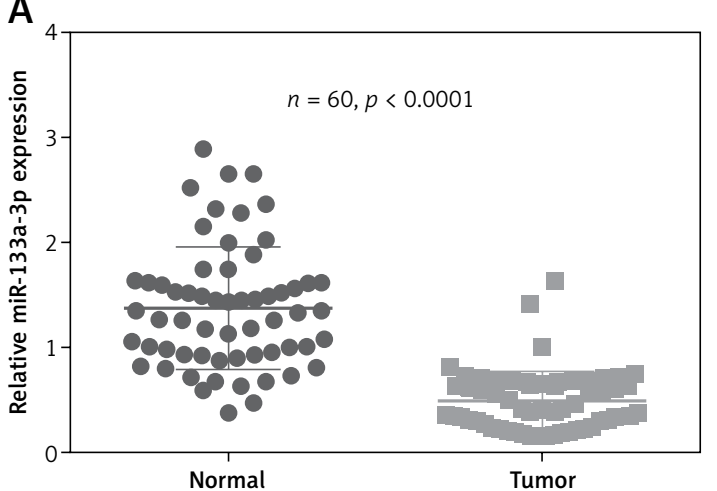

B

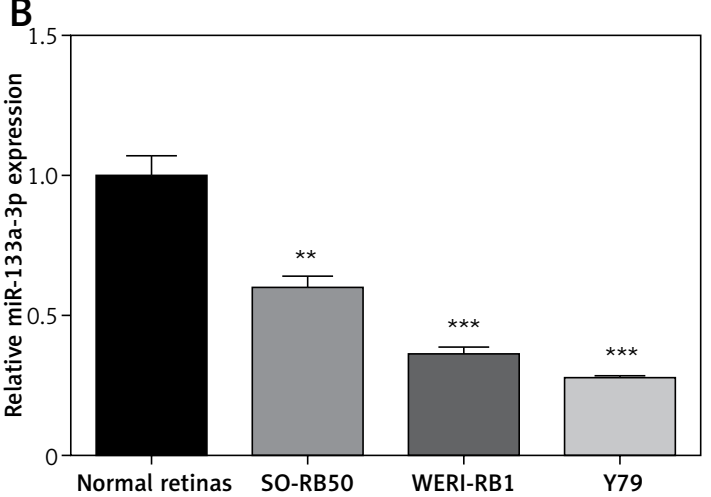

Figure 1. miR-133a-3p is down-regulated in retinoblastoma tissues and cell lines. qRT-PCR results show miR-133a$3 p$ levels in (A) cancerous and non-tumor tissues of retinoblastoma patients $(n=60)$, as well as (B) normal retinal cells in children and retinoblastoma RB50, WERI-RB1 and Y79 cells $(n=6)$

Data are presented as mean $\pm S D$. ${ }^{* *} p<0.01,{ }^{* * *} p<0.001$

expression was observed in miR-133a-3p inhibitor-transfected cells compared with the NC inhibitor group $(p<0.001)$ (Figure $2 \mathrm{~A})$.

We subsequently explored the effects of miR$133 a-3 p$ on the cell viability of $Y 79$ and WERI-RB1 cells. As shown in Figure $2 \mathrm{~B}$, overexpression of miR$133 a-3 p$ reduced cell viability while the suppression of miR-133a-3p resulted in the opposite effect $(p<0.001)$. Furthermore, apoptosis of transfected cells was measured using flow cytometry, which showed that the percentage of apoptotic cells in the miR-133a-3p mimic group was significantly higher than that in the NC mimic group, whereas inhibition of miR-133a-3p significantly decreased apoptosis (Figure 2 C, $p<0.001$ ). In addition, the effects of miR-133a-3p mimics or inhibitor on the cell cycle were also tested using flow cytometry. After $48 \mathrm{~h}$ of transfection, the number of cells in the G0/G1 phase was increased in the miR-133a$3 p$ mimic group compared to the NC mimic group, whereas transfection with miR-133a-3p inhibitor led to the opposite effects (Figure $2 \mathrm{D}$ ).

\section{CREB1 enhances cell viability and reduces apoptosis}

To explore the role of CREB1 in RB, we transfected pBabe-puro-CREB1 plasmids, pLKO.1-CREB1 plasmids or their corresponding negative controls into Y97 and WERI-RB1 cells. pBabe-puro-CREB1 enhanced the mRNA and protein expression levels of CREB1 in both cells, while pLKO.1-CREB1 decreased the CREB1 expression levels (Figures $3 \mathrm{~A}$ and $\mathrm{B}$, $p<0.001)$. Next, cell viability was measured by MTT assay following overexpression or inhibition of CREB1. As shown in Figure 3 C, pBabe-puro-CREB1 promoted $\mathrm{Y} 79$ and WERI-RB1 cell viability, whereas pLKO.1-CREB1 reduced cell viability $(p<0.01$ or $p<$ 0.001). Similarly, the apoptosis rate was decreased when CREB1 was overexpressed, but was higher in the pLKO.1-CREB1 group compared with the pLKO.1 group (Figure $3 \mathrm{D}, p<0.001$ ). These results demonstrated that CREB1 may be closely related to the survival of RB cells.

\section{miR-133a-3p targets CREB1 in RB cell models}

TargetScan (http://www.targetscan.org/) and miRanda (http://www.microrna.org) databases were used in miR-133a-3p target prediction, which identified CREB1 as the potential target. The conserved binding regions between miR-133a-3p and CREB1 are shown in Figure $4 \mathrm{~A}$. To further validate the interaction between miR-133a-3p and CREB1, CREB1 3' UTR-wt or CREB1 3' UTRmut was transfected with miR-133a-3p mimics or NC mimics into Y79 and WERI-RB1 cells. miR$133 a-3 p$ mimics induced luciferase activity when co-transfected with CREB1 3' UTR-wt ( $p<0.001)$. However, CREB1 3' UTR-mut and miR-133a-3p mimics' co-transfection had no effect on relative luciferase activity, demonstrating that miR133a-3p could directly target CREB1 (Figure 4 B). In addition, western blot results showed that miR-133a-3p overexpression led to reduction in expression of CREB1, pCREB1, CREM and BDNF in Y79 and WERI-RB1 cells (Figure 4 C, $p<0.001$ ).

\section{miR-133a-3p promotes apoptosis}

and induces cell cycle arrest by targeting

CREB1 in the RB cell model

The effects of miR-133a-3p and CREB1 on cell survival were assessed after Y97 and WERI-RB1 cells were co-transfected with miR-133a-3p mimics and pBabe-pur-CREB1 plasmids. Our results demonstrated that CREB1 overexpression rescued miR-133a-3p mimic-induced cell viability reduction in both cell lines (Figure $5 \mathrm{~A}, p<0.001$ ). The number of cells in G0/G1 phase was also reduced and $S$ phase cell numbers were increased when CREB1 and miR-133a-3p were co-overexpressed (Figure 5 B). Moreover, cyclin B1 and cyclin D1 (cell 
A
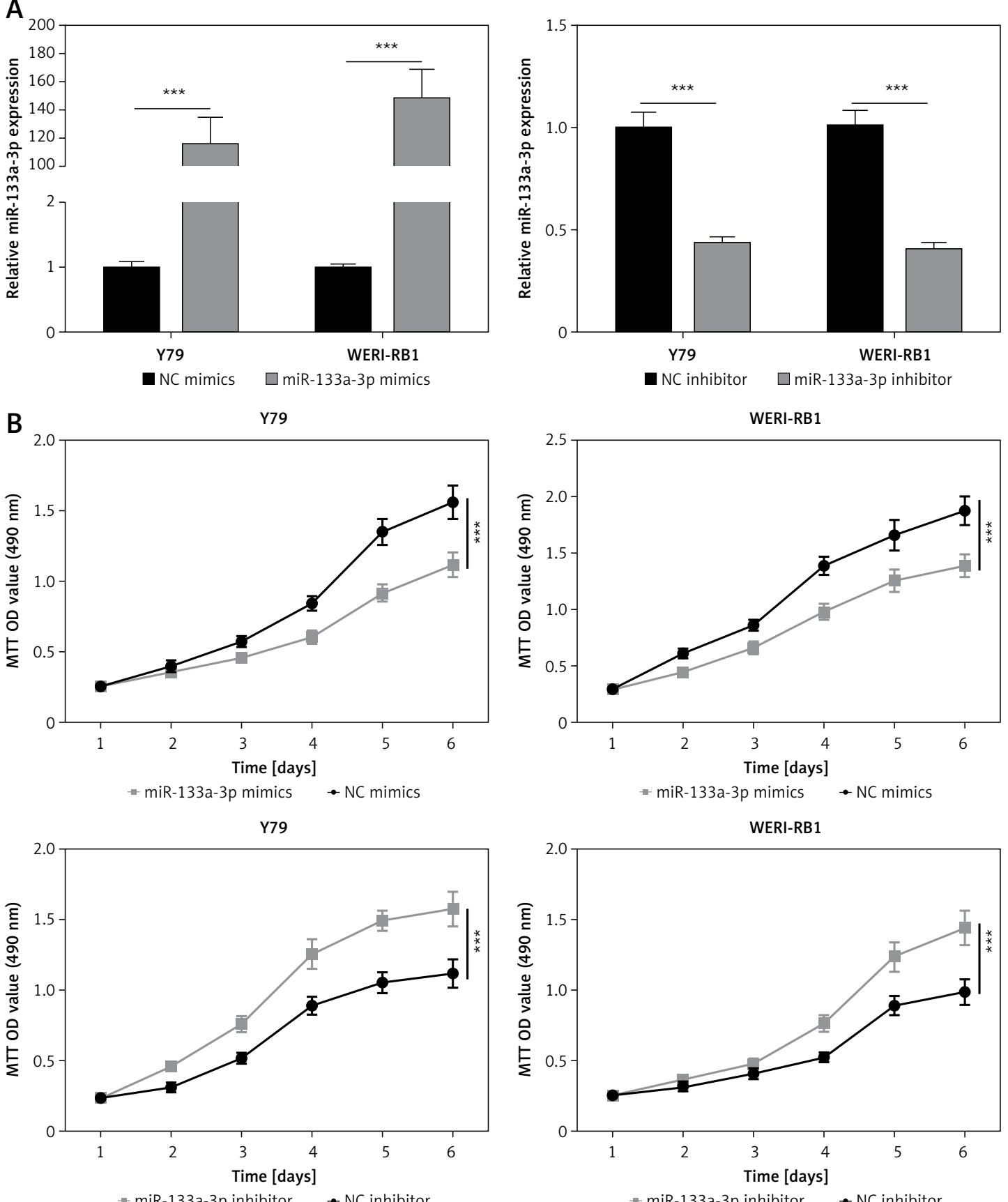

Figure 2. miR-133a-3p inhibits cell viability, increases apoptosis and cell cycle arrest in WERI-RB1 and Y79 cells. A - qRT-PCR results showing the transfection efficiency of miR-133a-3p. B - MTT assay tested the effects of miR$133 a-3 p$ mimics and inhibitors on cell viability

Data are presented as mean $\pm S D, n=6 .{ }^{* * *} p<0.001$.

cycle related proteins) expression levels were reduced in the miR-133a-3p mimic group compared with NC mimics, which were abolished when CREB1 and miR-133a-3p were overexpressed (Figure $5 \mathrm{C}, p<0.001)$.

Furthermore, the flow cytometry results indicated that pBabe-puro-CREB1 diminished apoptosis mediated by miR-133a-3p mimics (Figure $6 \mathrm{~A}$, $p<0.001$ ), suggesting that CREB1 may be involved in the anti-apoptotic effect of miR-133a-3p. In ad- dition, we found that miR-133a-3p overexpression resulted in the reduction of CREB1 and $\mathrm{Bcl}-2$, as well as increase in Bax and cleaved caspase-3, which were counteracted by transfection with pBabe-puro-CREB1 (Figure 6 B, $p<0.001$ ).

\section{miR-133a-3p inhibits tumor growth in vivo}

In order to study the effects of miR-133a-3p on the growth of RB in vivo, the RB xenograft mouse 
C

Y79

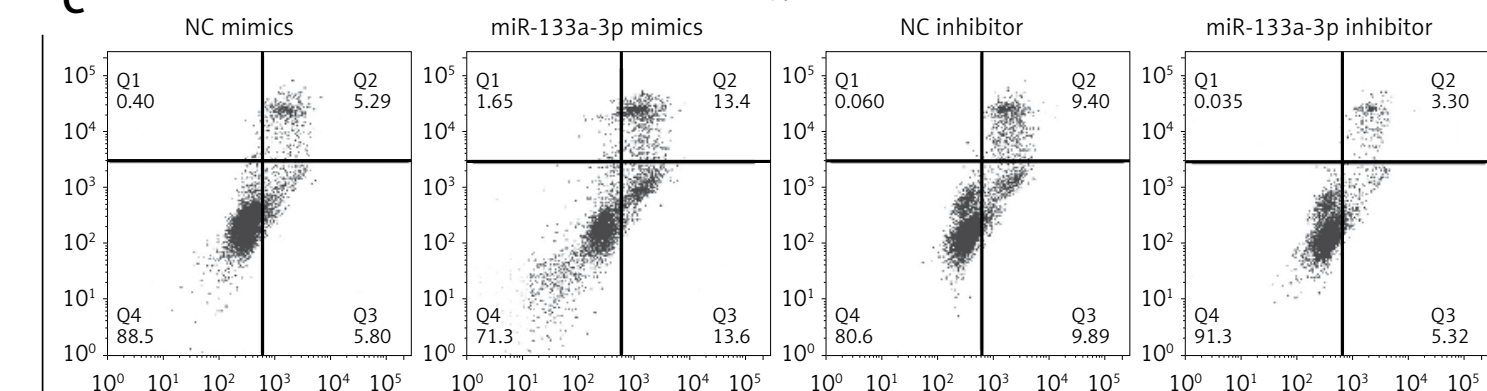

PI

WERI-RB1

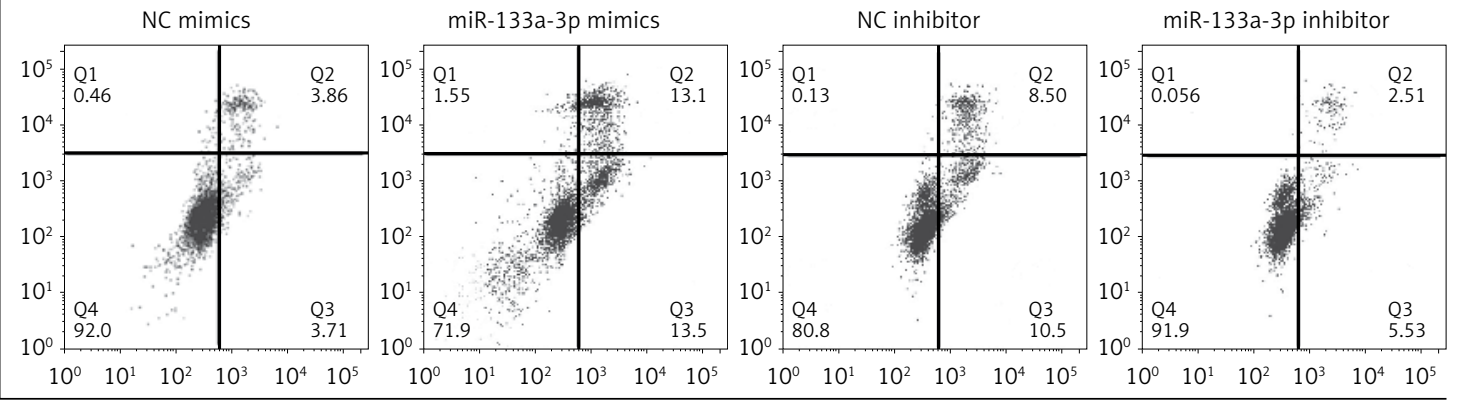

Annexin V
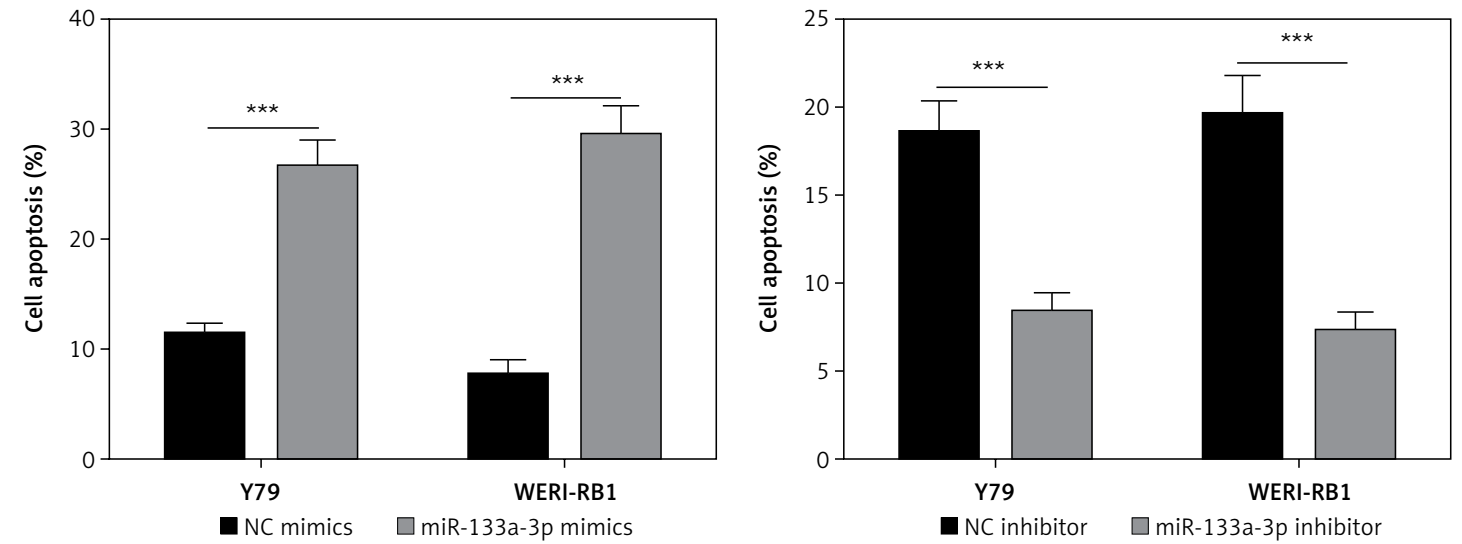

Figure 2. Cont. Flow cytometry assay explored the influence of miR-133a-3p mimics and inhibitors in apoptosis (C) and cell cycle (D)

Data are presented as mean $\pm S D, n=6 .{ }^{* * *} p<0.001$.

models were established by injecting $Y 79$ cells transfected with miR-133a-3p mimics or NCs. We found that the average weight and volume of tumors were significantly lower in the miR-133a-3p group compared to the control group (Figure 7 , $p<0.001)$. These findings demonstrated the potential anti-tumor properties of miR-133a-3p in vivo.

\section{Discussion}

Although the biological functions of miR-133a$3 p$ remain unclear, miR-133a-3p has been reported to play an anti-tumor role in the development of cancers, including bladder cancer, breast cancer and gastric cancer $[12,13,24]$. In a study by Huang et al., they reported that miR-133a-3p promotes apoptosis and inhibits cell proliferation and migration in gallbladder carcinoma [25]. Li et al. also described the inhibitory action of miR-133a$3 p$ in gastric cancer cell proliferation [13]. On the basis of these findings, we hypothesized that miR133a-3p overexpression may be a promising option in cancer therapy. However, the function and mechanism of miR-133a-3p in RB remain to be elucidated. Hence, we investigated the effects of miR-133a-3p on RB in this study, and found the down-regulation of miR-133a-3p level in RB tissues and cell models. Furthermore, miR-133a-3p overexpression reduced RB cell viability and promoted apoptosis. Similarly, miR-133a-3p overexpression also suppressed tumor size and weight in vivo. These results are consistent with previous findings. A large number of studies have shown the regulatory role played by $\mathrm{miR}-133 \mathrm{a}$ in cell de- 

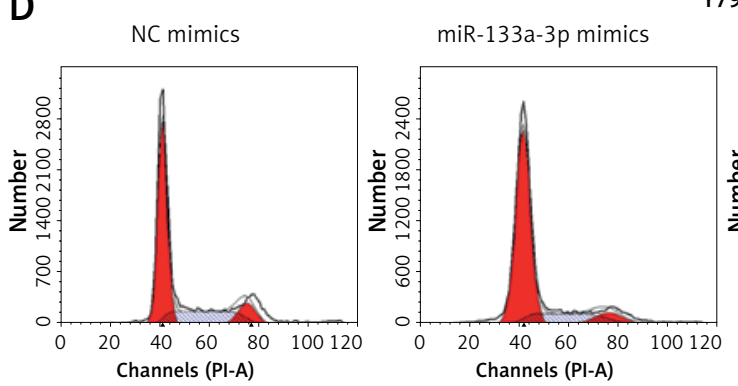

$\square$ Dip G1

NC mimics

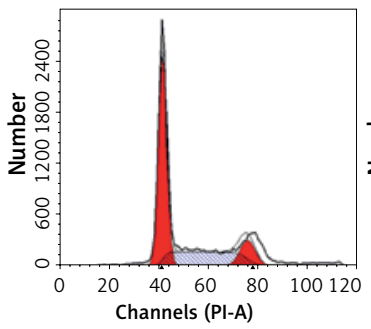

miR-133a-3p mimics

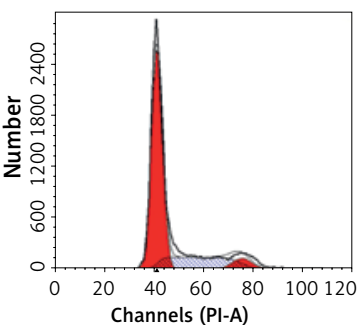

$\square$ Dip G1

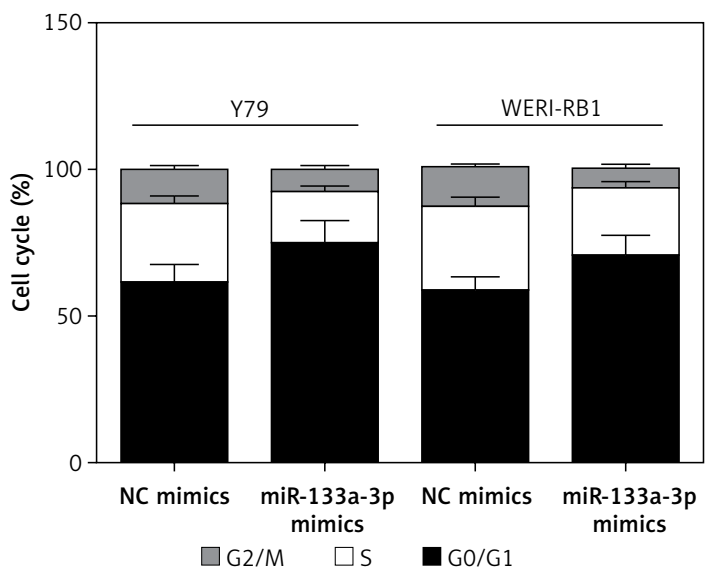

Y79
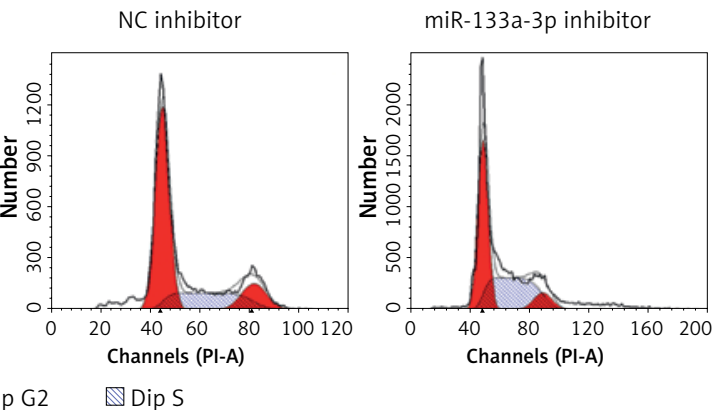

WERI-RB1
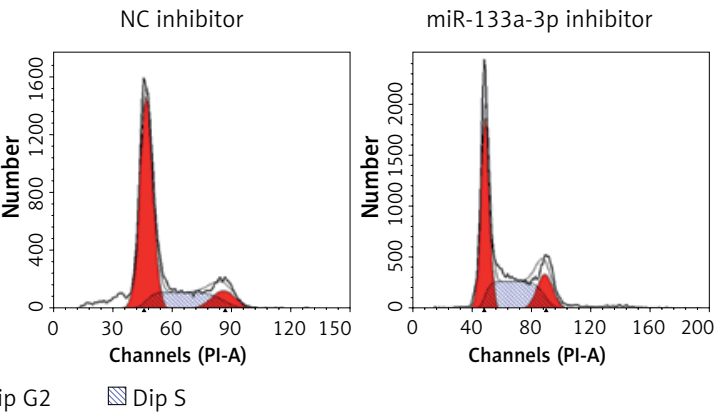

Figure 2. Cont. Flow cytometry assay explored the influence of miR-133a-3p mimics and inhibitors in apoptosis (C) and cell cycle (D)

Data are presented as mean $\pm S D, n=6 .{ }^{* * *} p<0.001$

velopment in tumors through regulating target genes such as LASP1, RBP-J and ERBB2 [12, 13, 25]. In this study, CREB1 was predicted to be the potential target gene of miR-133a-3p by bioinformatic analysis. As a transcription factor of the basic leucine zipper (bZIP) family, CREB1 is a wellknown key proto-oncogene that has recently been identified as a direct target of other miRNAs, including miR-200b miR-1224-5p, miR-34b, miR-9 and miR-373 [21, 22, 26, 27]. In our study, luciferase reporter assay further verified the specific binding between CREB1 and miR-133a-3p. Moreover, western blot results showed that miR-133a$3 p$ inhibited the expression of CREB1, CREM and its downstream protein BDNF, indicating that miR133a-3p may inhibit the CREB pathway.

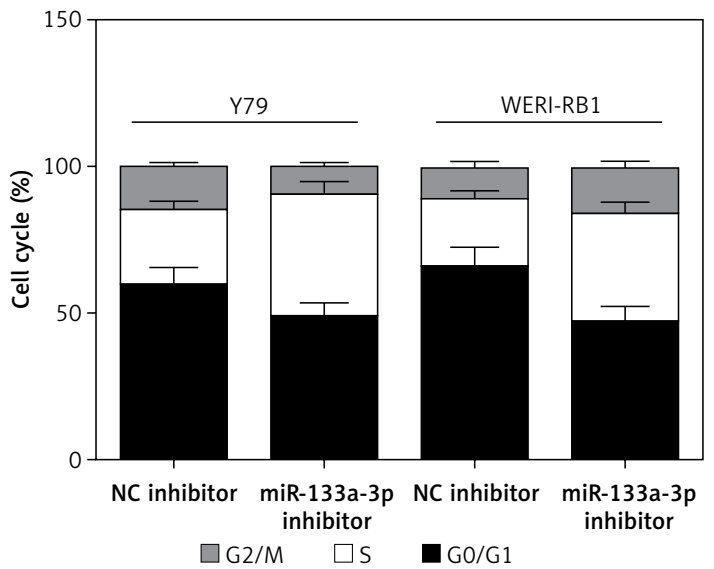

A previous study showed that aberrant activation of oncogenes leads to cancer cells being exposed to apoptotic stress during malignant transformation [28]. In order to prevent cell death, cancer cells up-regulate anti-apoptotic signals to suppress apoptosis [28]. Analogously, studies have reported that inositol-6 phosphate (IP-6) and IncRNA UBE2CP3-001 inhibit apoptosis in some cancers [29, 30]. Furthermore, CREB1 overexpression is associated with increased cell proliferation and decreased apoptotic sensitivity [31, 32]. In our study, cell viability was increased and apoptosis was decreased when CREB1 was overexpressed in the RB cell model, which is consistent with the findings from Qian et al. on malignant glioma cells [26]. Interestingly, we revealed that the pro-apop- 

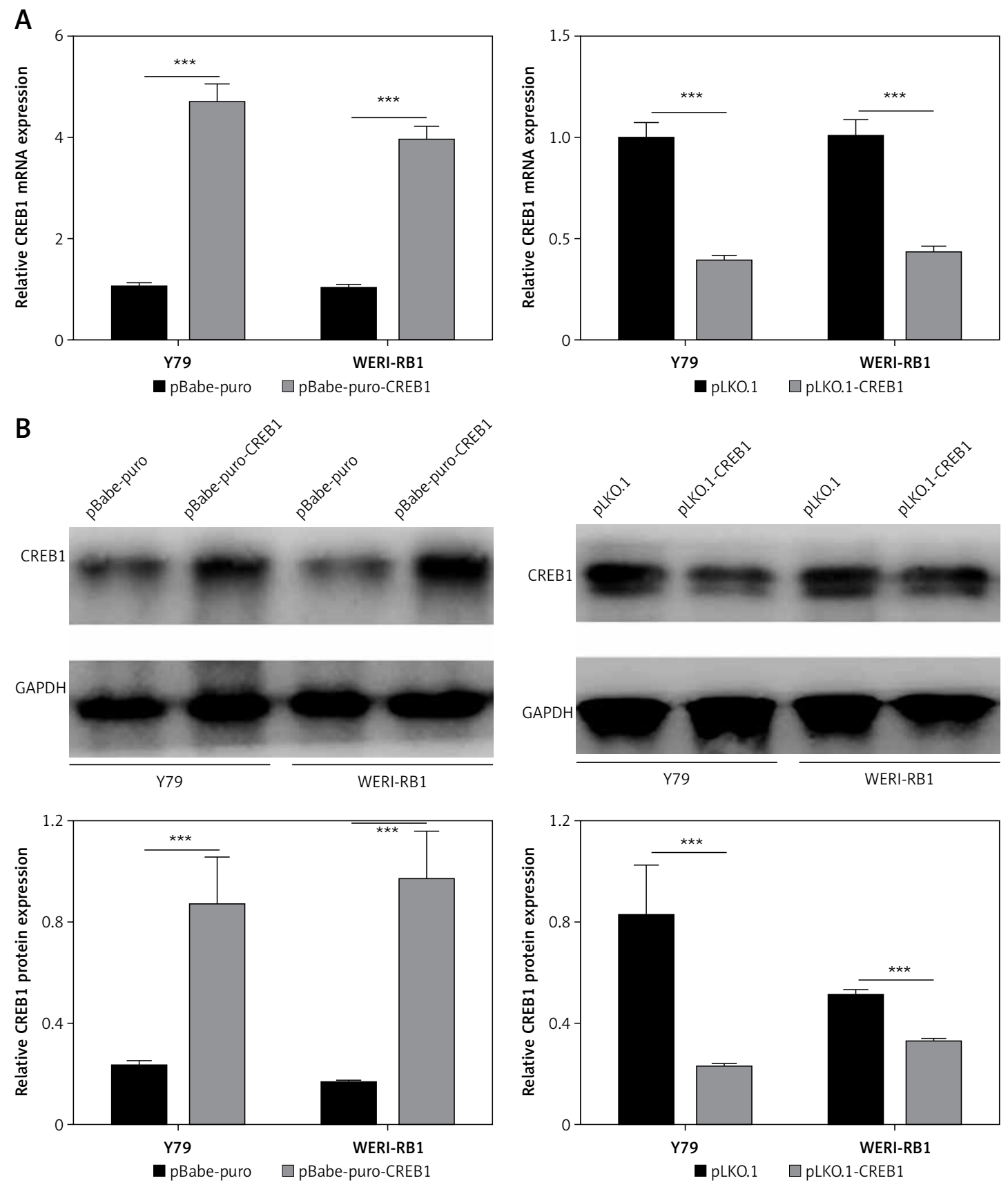

Figure 3. CREB1 enhances cell viability and reduces apoptosis in WERI-RB1 and Y79 cells. A - The mRNA levels of CREB1 were measured after transfecting pBabe-puro-CREB1 or pLKO.1-CREB1 plasmids into cells. B - Western blot results showing CREB1 protein levels

Data are expressed as mean $\pm S D, n=6 .{ }^{* *} p<0.01,{ }^{* * *} p<0.001$.

totic function of miR-133a-3p was reversed by CREB1 overexpression. The overexpression of CREB1 attenuated the miR-133a-3p-induced increase in apoptosis, Bax and cleaved caspase-3, as well as decreasing Bcl-2. These results illustrated that the pro-apoptosis of miR-133a-3p was targeted by CREB1. Previous studies have demonstrated that CREB1 regulates cell proliferation through cell-cycle arrest [24, 33]. Zhang et al. reported that CREB1-induced histone $\mathrm{H} 3$ acetylation facilitates the transition of $\mathrm{GO}$ to $\mathrm{S}$ phase cells in prostate cancer [34]. In addition, CREB1 has been reported to be able bind to the promoters of cell cycle genes, including cyclin A, B1, D1, D2 and Wnt10b and regulates the transcription of these genes, thereby regulating cell proliferation $[31,35]$. Similarly, this study revealed that miR-133a-3p prevented the transition from $\mathrm{G} 1$ to $\mathrm{S}$ phase in $\mathrm{Y} 97$ cells, causing cell cycle arrest and down-regulation of cyclin B1 and D1. Subsequently, CREB1 overexpression abolished miR-133a-3p0-mediated effects, suggesting that miR-133a-3p regulates 

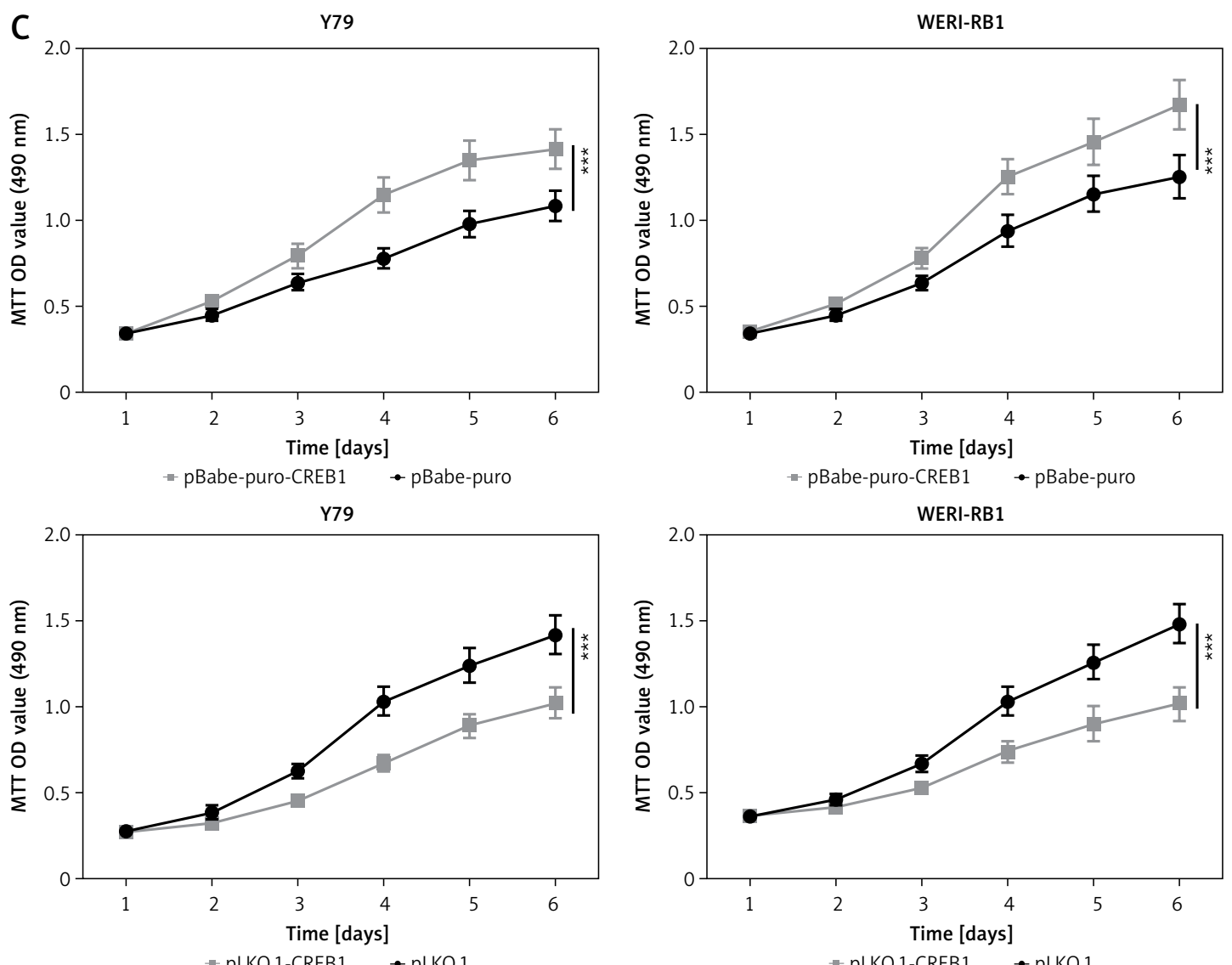

D $\quad$ Y79

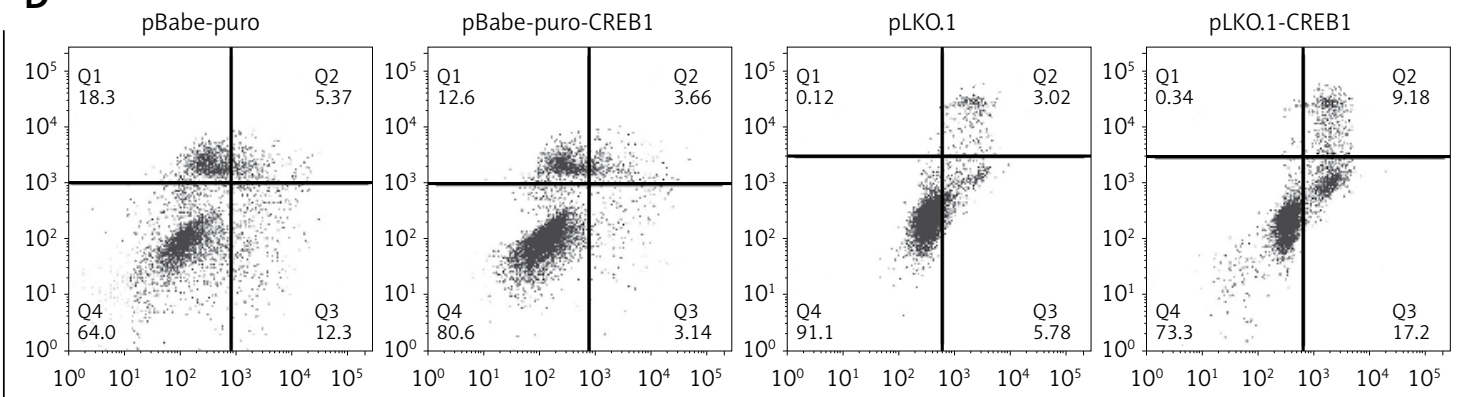

$\mathrm{PI}$

WERI-RB1

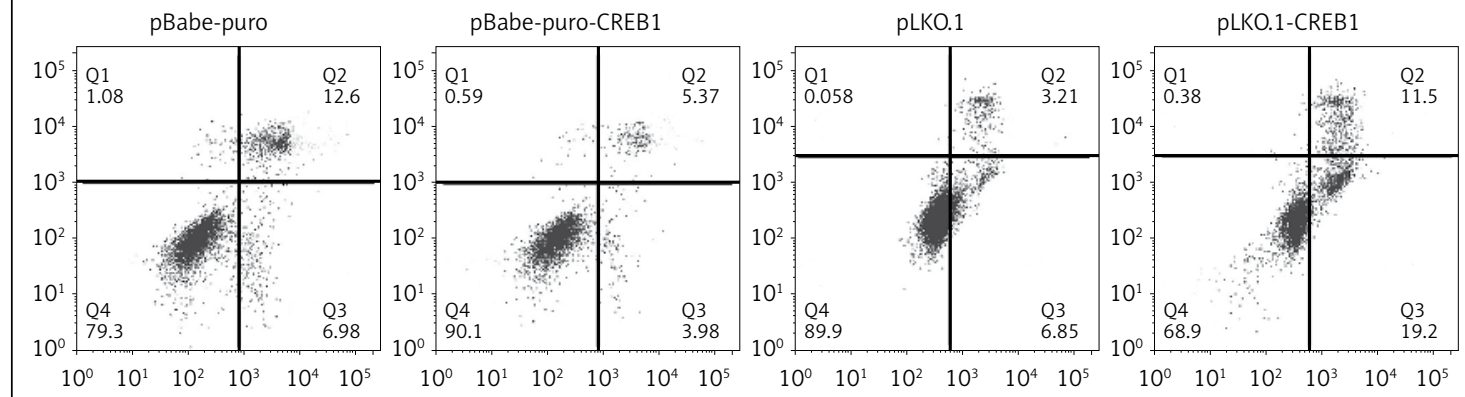

Annexin V
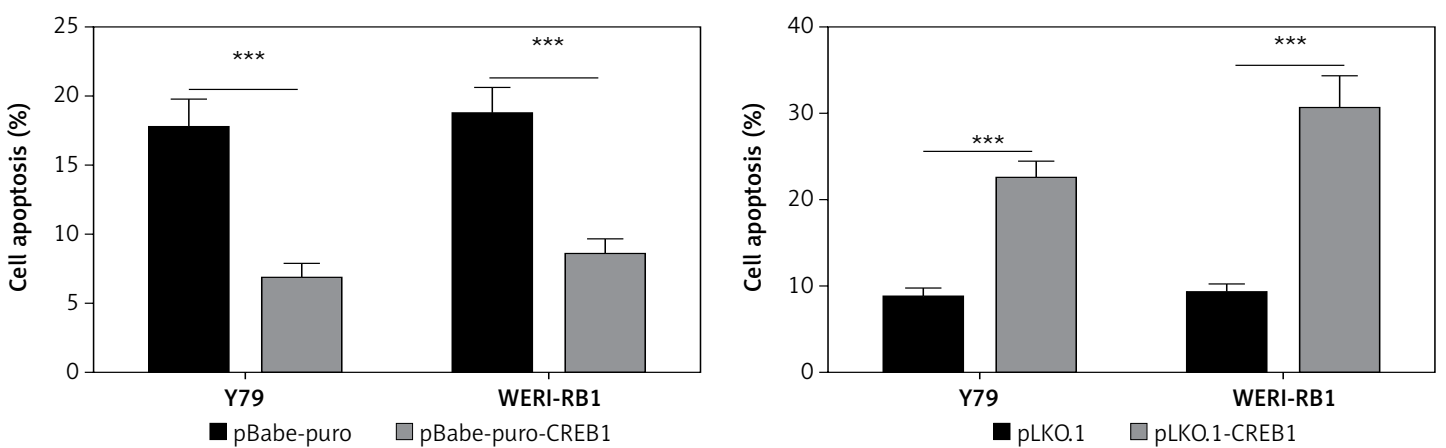

Figure 3. Cont. C - The effects of pBabe-puro-CREB1 or pLKO.1-CREB1 on cell viability determined by MTT assay. D - The effect of pBabe-puro-CREB1 or pLKO.1-CREB1 on cell apoptosis determined by flow cytometry Data are expressed as mean $\pm S D, n=6 .{ }^{* *} p<0.01$, ${ }^{\star * *} p<0.001$. 
A

$\begin{array}{ll}\text { Position 5103-5109 of CREB1 3'UTR } & \text { 5'...AGACCGACUUUAAGAGGGACCAG... } \\ \text { hsa-miR-133a-3p.1 } & \text { 3' }\end{array}$

3' GUCGACCAACUUCCCCUGGUUU 5' hsa-miR-133a

7434:5' UUUCUUAAGUGCAGUGACCAAA 3' CREB1
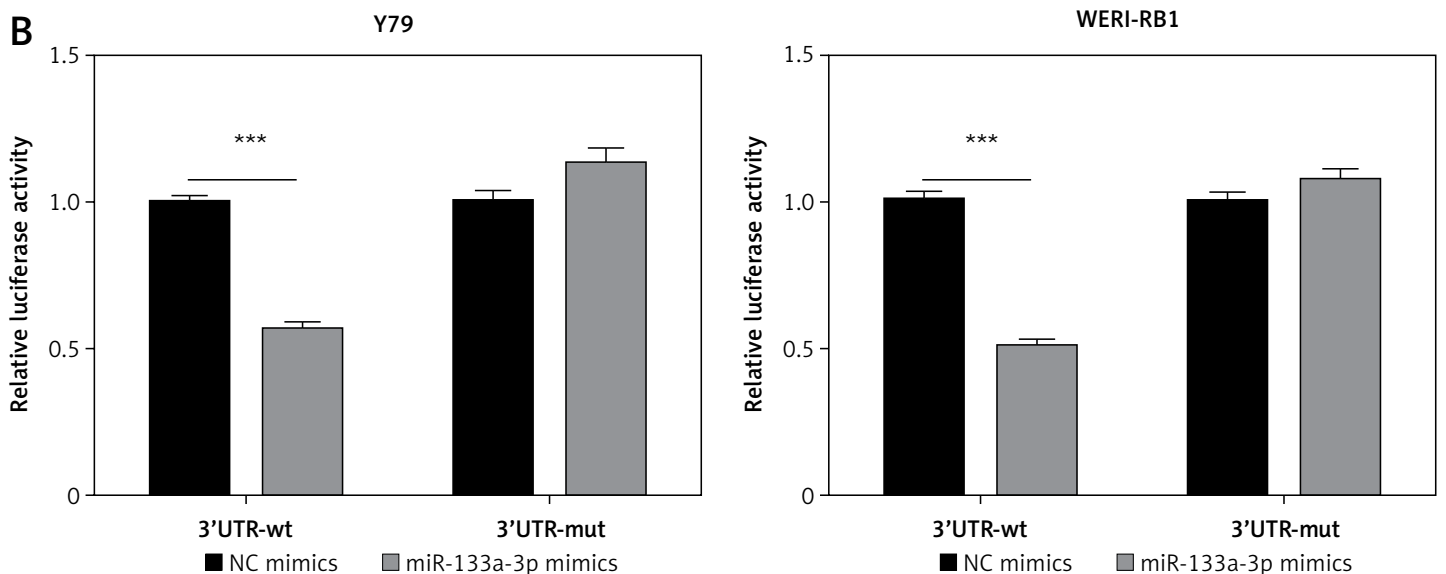

C
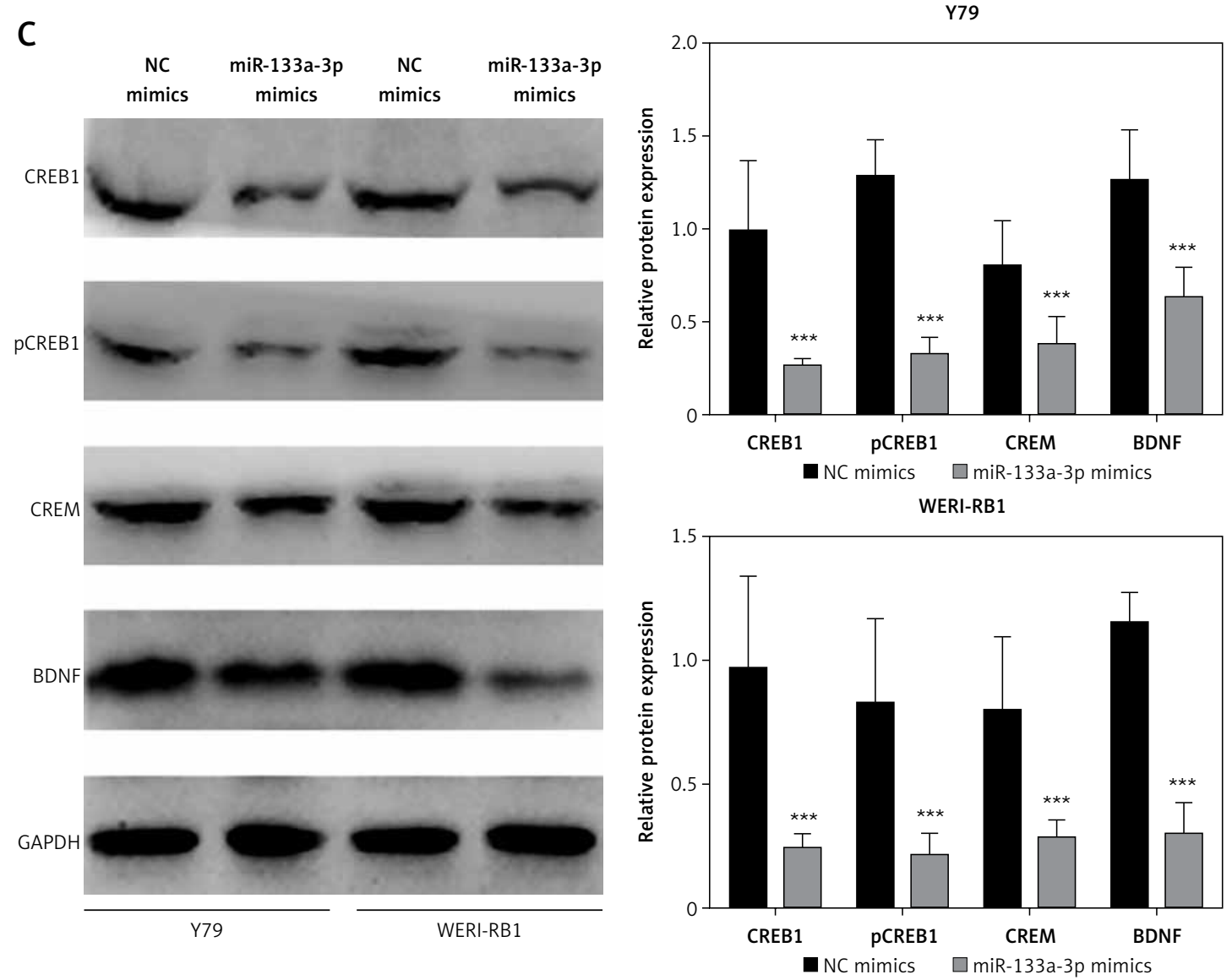

Figure 4. miR-133a-3p targets CREB1 in retinoblastoma cell model. A - The predicted binding sequences of miR133a-3p and CREB1. B - Dual luciferase reporter assay confirmed the binding between miR-133a-3p and CREB1. $\mathrm{C}$ - Western blots show CREB1, pCREB1, CREM and BDNF protein expression levels

Data are expressed as mean $\pm S D, n=6 .{ }^{* * *} p<0.001$. 


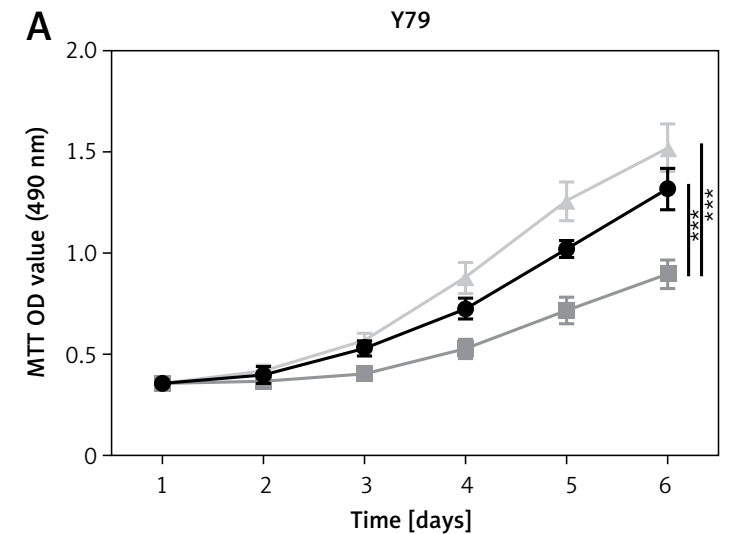

- miR-133a-3p mimics + pBabe-puro-CREB1

$\rightarrow$ miR-133a-3p mimics $\quad \longrightarrow$ NC mimics

B
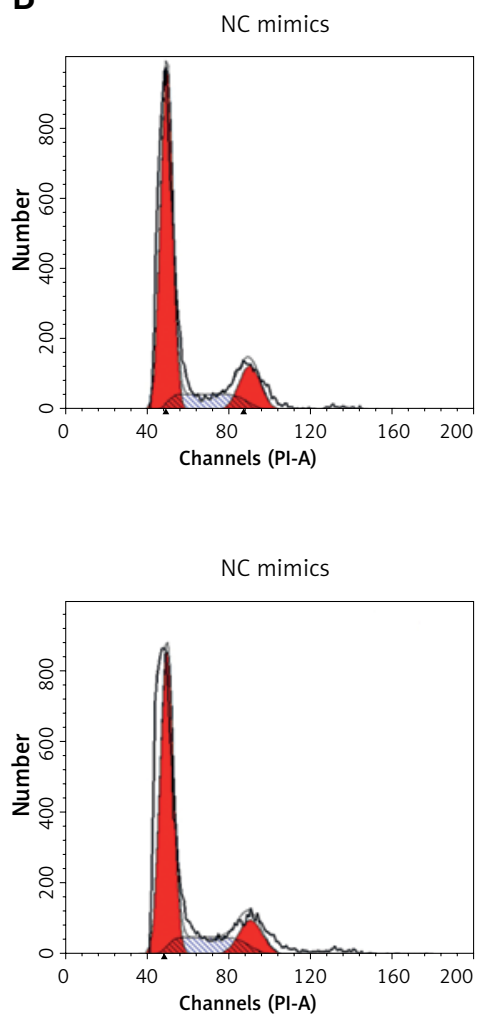

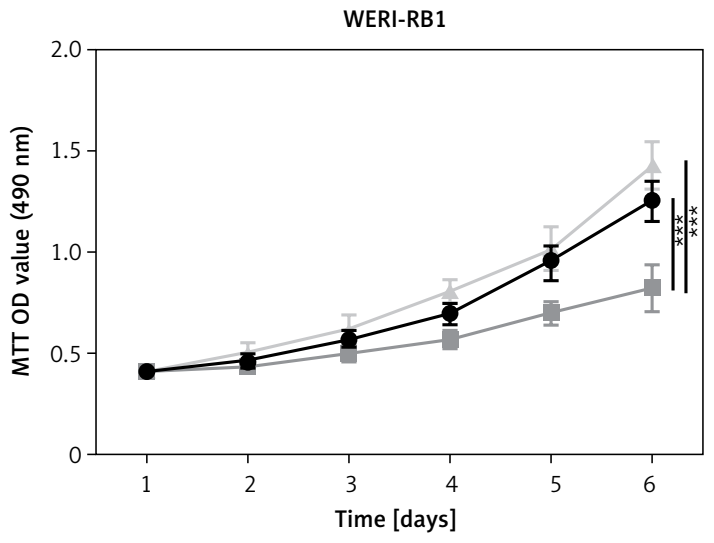

- miR-133a-3p mimics + pBabe-puro-CREB1

$\rightarrow$ miR-133a-3p mimics $\quad$ NC mimics

Y79

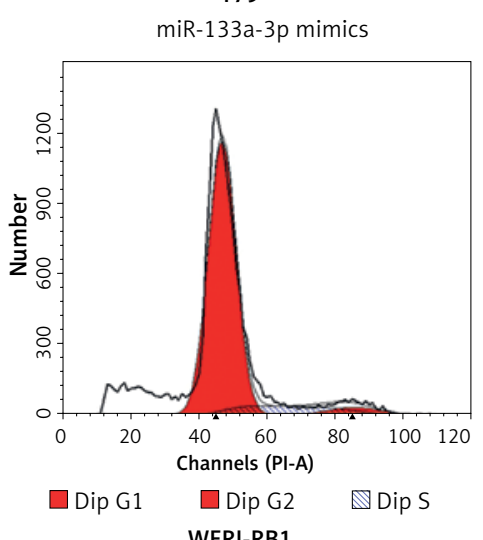

miR-133a-3p mimics + pBabe-puro-CREB1

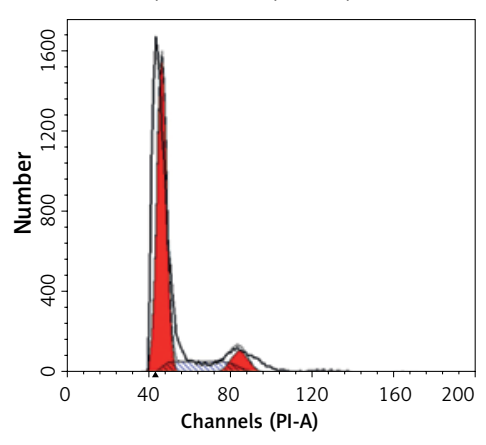

WERI-RB1

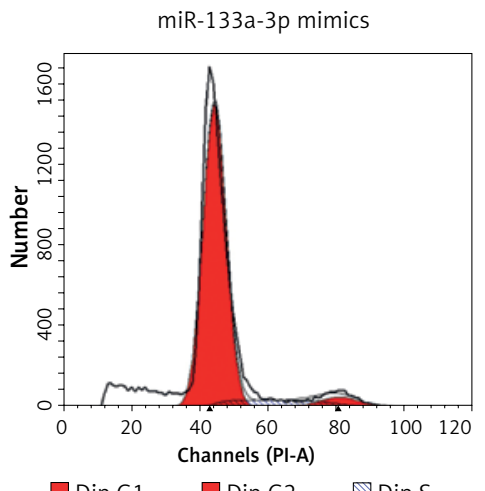

miR-133a-3p mimics + pBabe-puro-CREB1

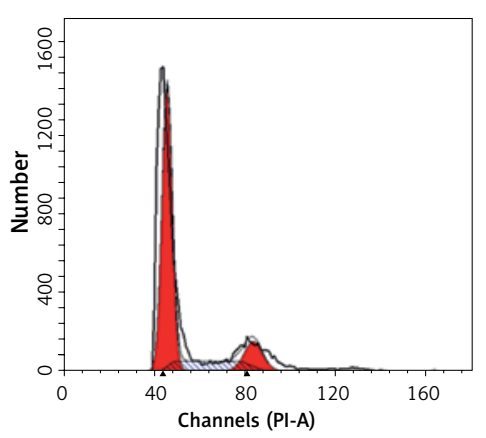

WERI-RB1
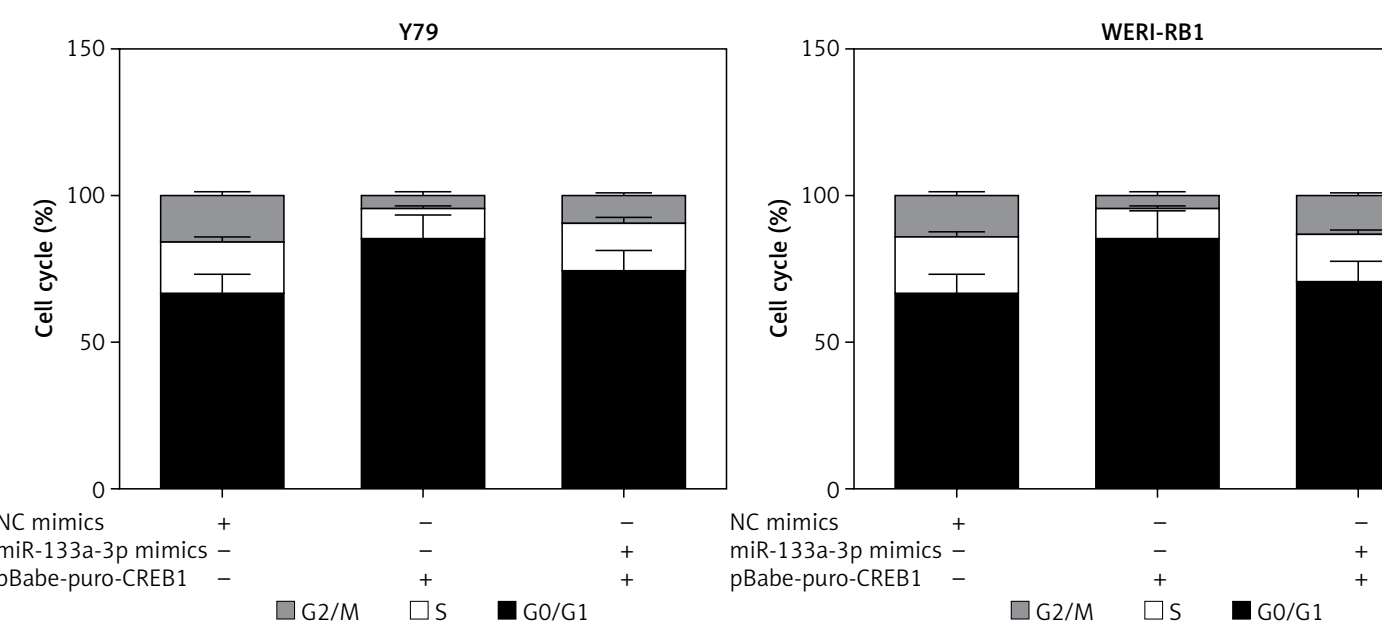

Figure 5. miR-133a-3p inhibits cell viability and induces cell cycle arrest by targeting CREB1 in retinoblastoma cell model. A - The influence of co-transfection with miR-133a-3p mimics and pBabe-pur-CREB1 plasmids in cell viability determined by MTT assay. B - The effects of co-transfection with miR-133a-3p mimics and pBabe-pur-CREB1 plasmids on cell cycle determined by flow cytometry

Data are expressed as mean $\pm S D, n=6 .{ }^{* * *} p<0.001$. 
C

NC mimics

miR-133a-3p mimics

pBabe-puro-CREB1

CREB 1

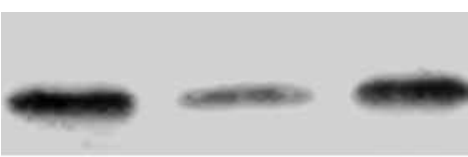

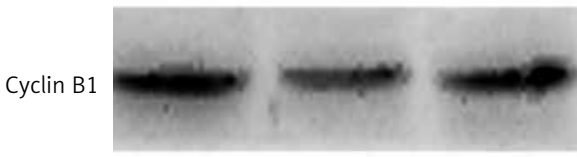
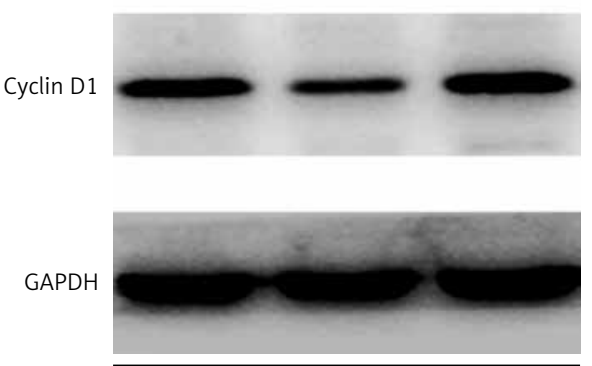

Y79

Y79

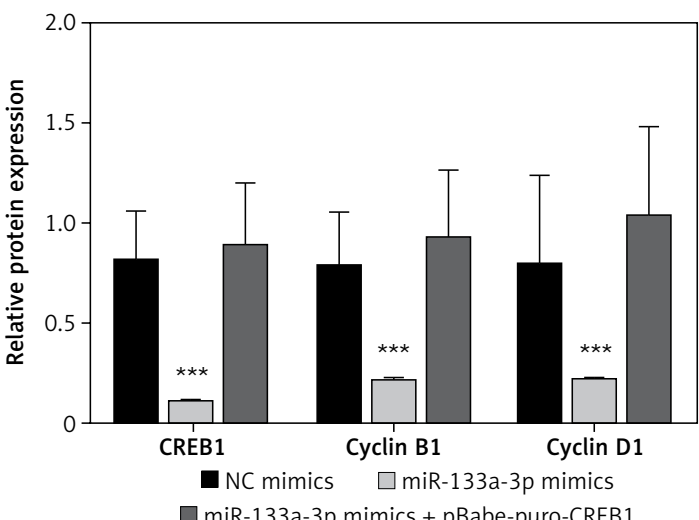

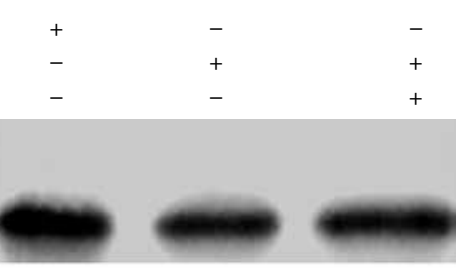
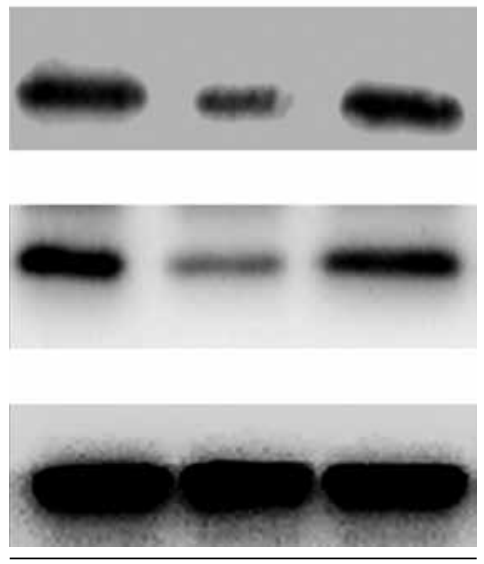

WERI-RB1

WERI-RB1

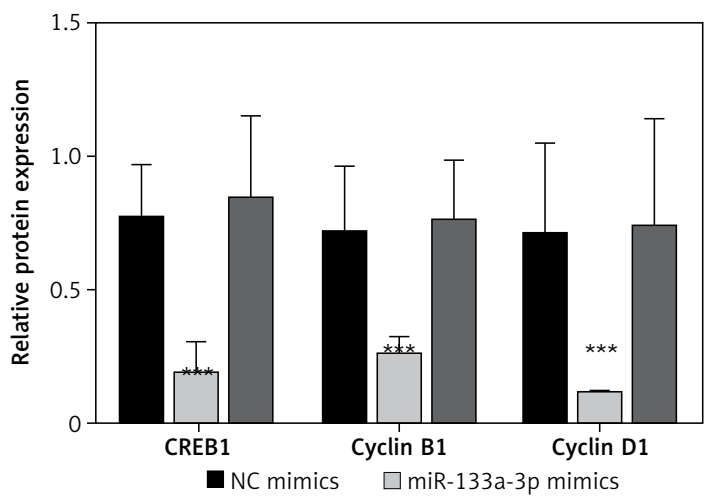

$\square$ miR-133a-3p mimics + pBabe-puro-CREB1

Figure 5. Cont. $\mathbf{C}$ - Western blots show the protein expression levels of CREB1, cyclin B1 and cyclin D1

Data are expressed as mean $\pm S D, n=6 .{ }^{* * *} p<0.001$.

the CREB1-mediated cell cycle. These findings are consistent with the report from Pigazzi et al. that miRNAs function as tumor suppressors via negatively regulating $C R E B 1$ and its targets including Bcl-2, cyclin B1 and cyclin D1 [36].

In conclusion, these results indicate that miR133a-3p overexpression inhibits tumor development, promotes apoptosis and induces cell cycle arrest by targeting CREB 1 in vivo and in RB cell models. This study has improved our understanding of the pathogenesis of RB, and provides a new direction for effective targeted treatment of RB. However, one of the limitations of this study is that we have just preliminarily explored the anti-tumor influence of miR-133a-3p in the nude mouse model of RB. Further in vivo studies are required to further validate the inhibitory effects and the underlying mechanisms of miR-133a-3p in RB.

\section{Conflict of interest}

The authors declare no conflict of interest. 
A

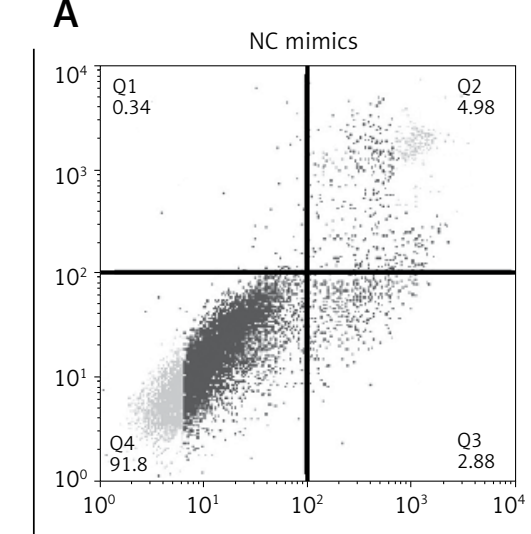

PI

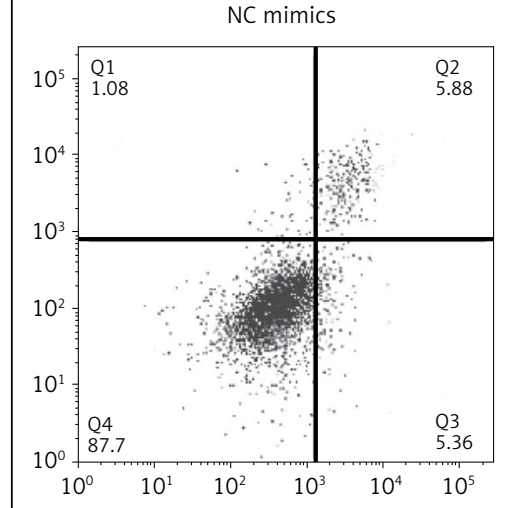

Y79

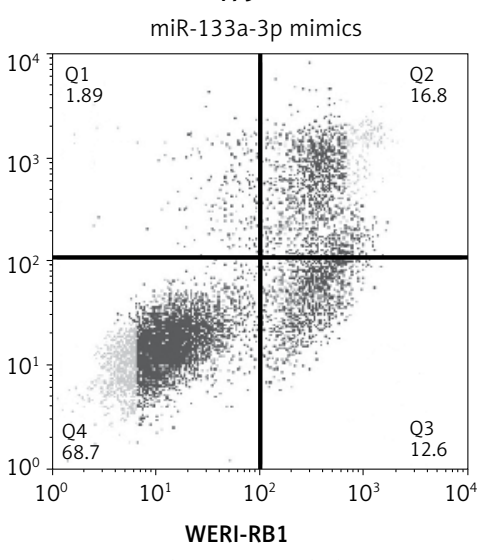

miR-133a-3p mimics + pBabe-puro-CREB1

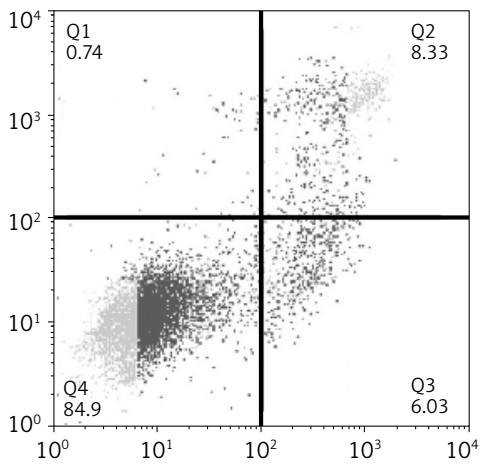

miR-133a-3p mimics + pBabe-puro-CREB1
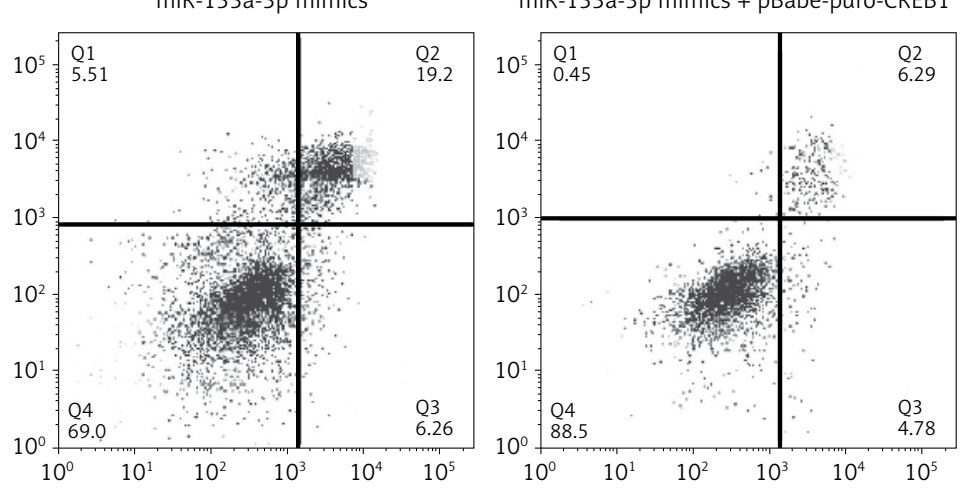

Annexin V
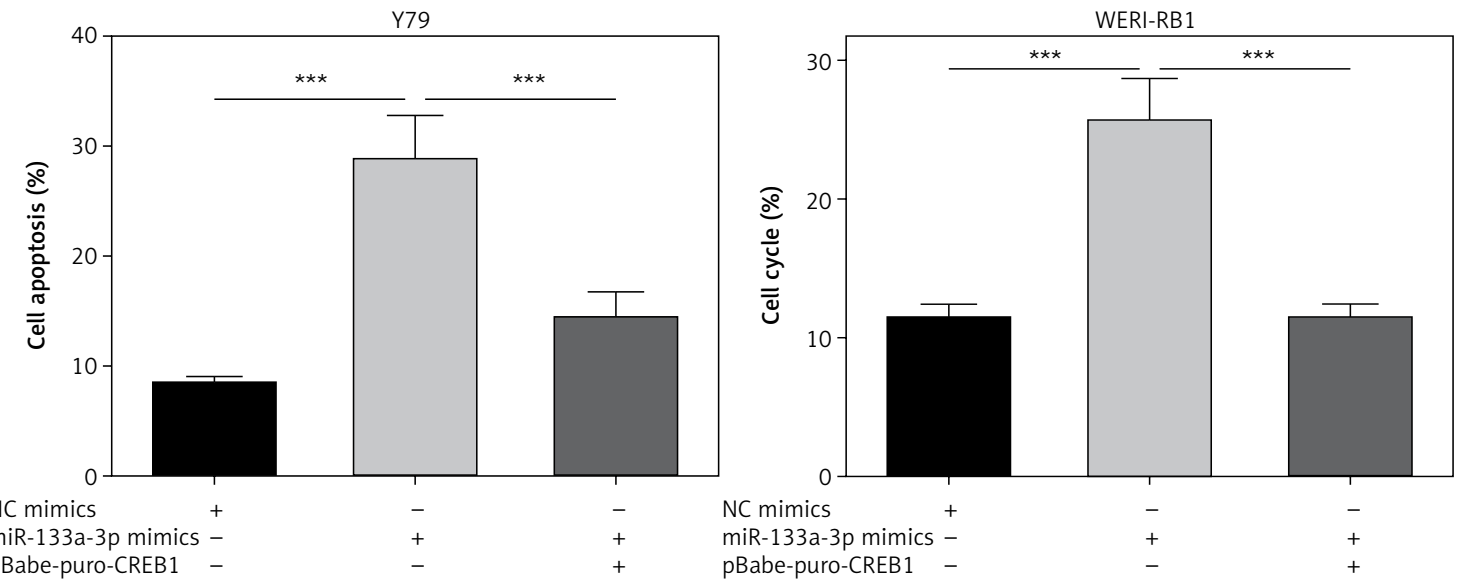

Figure 6. miR-133a-3p promotes cell apoptosis by targeting CREB1 in retinoblastoma cell model. A - The effect of co-transfection with miR-133a-3p mimics and pBabe-pur-CREB1 plasmids on cell apoptosis determined by flow cytometry

Data are expressed as mean $\pm S D, n=6 .{ }^{* * *} p<0.001$. 
B

NC mimics

miR-133a-3p mimics

pBabe-puro-CREB1

CREB1

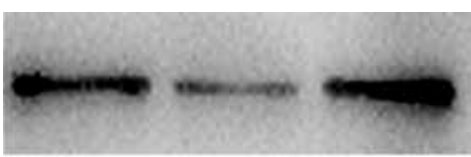

$\mathrm{Bcl}-2$

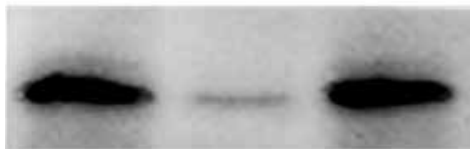

Bax

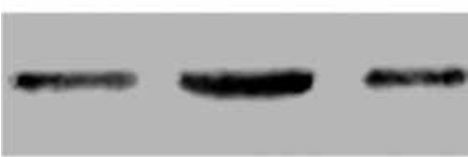

Cleaved caspase-3

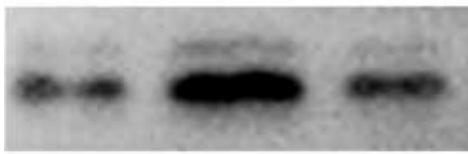

GAPDH

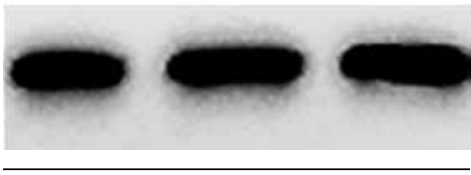

Y79

Y79

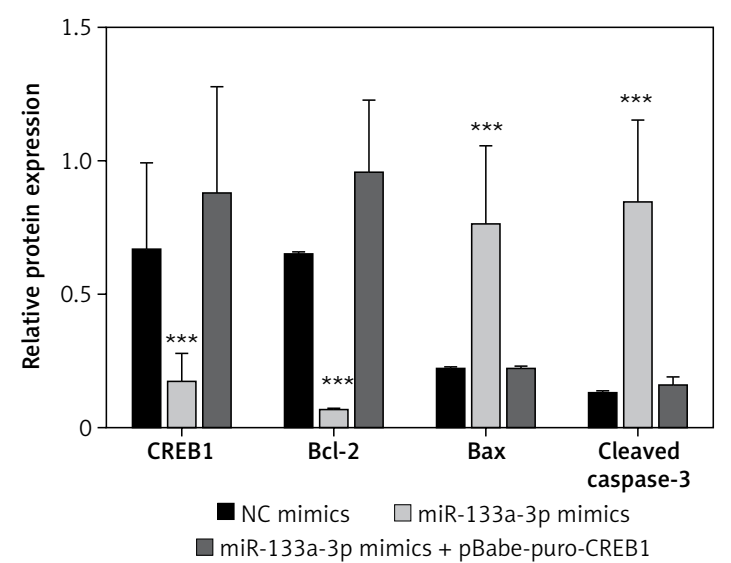

WERI-RB1

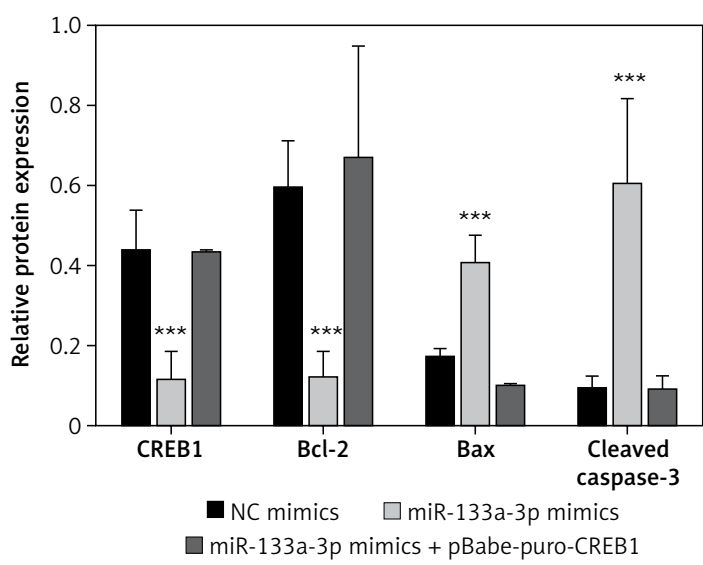

Figure 6. Cont. B - Western blots showing protein levels of CREB1, Bcl-2, Bax and cleaved caspase-3

Data are expressed as mean $\pm S D, n=6 .{ }^{* * *} p<0.001$. 

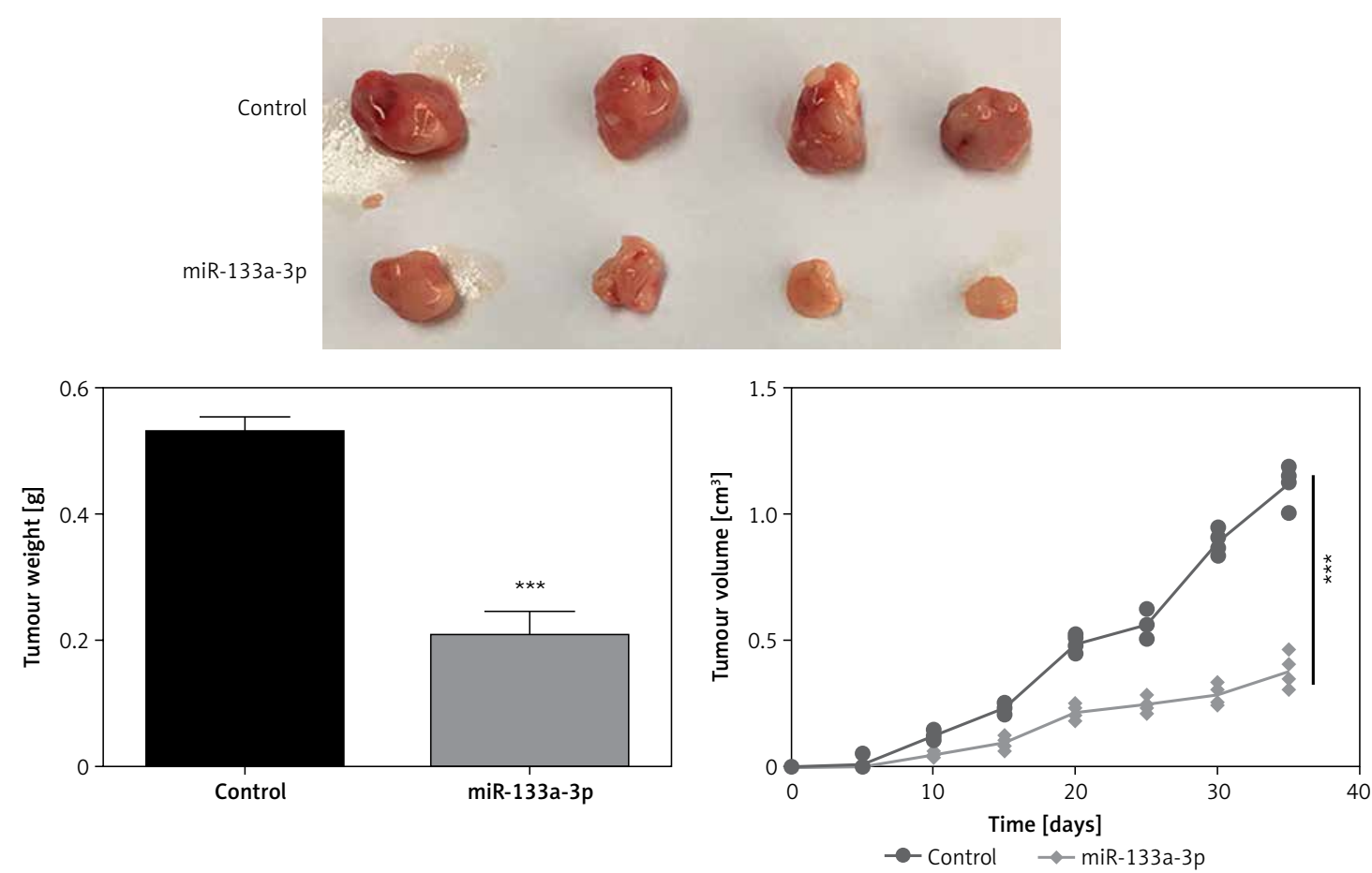

Figure 7. miR-133a-3p inhibits RB growth in vivo. Y79 cells transfected with miR-133a-3p mimics or the negative control were subcutaneously injected into nude mice for 40 days. The average weight and volume of tumor were measured

Data are presented as mean $\pm S D, n=4 .{ }^{* * *} p<0.001$.

\section{References}

1. Dimaras H, Kimani K, Dimba E, et al. Retinoblastoma. Lancet 2012; 379: 1436-46.

2. Abramson DH. Retinoblastoma: saving life with vision. Annu Rev Med 2014; 65: 171-84.

3. Dyer MA. Lessons from retinoblastoma: implications for cancer, development, evolution, and regenerative medicine. Trends Mol Med 2016; 22: 863-76.

4. Mendoza PR, Grossniklaus HE. Therapeutic options for retinoblastoma. Cancer Control 2016; 23: 99-109.

5. Hayes J, Peruzzi PP, Lawler S. MicroRNAs in cancer: biomarkers, functions and therapy. Trends Mol Med 2014; 20: 460-9.

6. Leichter AL, Sullivan MJ, Eccles MR, Chatterjee A. MicroRNA expression patterns and signalling pathways in the development and progression of childhood solid tumours. Mol Cancer 2017; 16: 15.

7. Nazarov PV, Reinsbach SE, Muller A, et al. Interplay of microRNAs, transcription factors and target genes: linking dynamic expression changes to function. Nucleic Acids Res 2013; 41: 2817-31.

8. Yang M, Zhang L, Wang X, Zhou Y, Wu S. Down-regulation of miR-203a by IncRNA PVT1 in multiple myeloma promotes cell proliferation. Arch Med Sci 2018; 14: 1333-9.

9. Nittner D, Lambertz I, Clermont F, et al. Synthetic lethality between $\mathrm{Rb}, \mathrm{p} 53$ and dicer or miR-17-92 in retinal progenitors suppresses retinoblastoma formation. Nat Cell Biol 2012; 14: 958-65.

10. Wang J, Wang X, Wu G, Hou D, Hu Q. MiR-365b-3p, down-regulated in retinoblastoma, regulates cell cycle progression and apoptosis of human retinoblastoma cells by targeting PAX6. FEBS Lett 2013; 587: 1779-86.

11. Lei Q, Shen F, Wu J, Zhang W, Wang J, Zhang L. MiR-101, downregulated in retinoblastoma, functions as a tumor suppressor in human retinoblastoma cells by targeting EZH2. Oncol Rep 2014; 32: 261-9.

12. Sui Y, Zhang X, Yang H, Wei W, Wang M. MicroRNA-133a acts as a tumour suppressor in breast cancer through targeting LASP1. Oncol Rep 2018; 39: 473-82.

13. Li C, Li X, Gao S, Li C, Ma L. MicroRNA-133a inhibits proliferation of gastric cancer cells by downregulating ERBB2 expression. Oncol Res 2017; 25: 1169-76.

14. Wei W, Liu Y, Lu Y, Yang B, Tang L. LnCRNA XIST promotes pancreatic cancer proliferation through miR-133a/EGFR. J Cell Biochem 2017; 118: 3349-58.

15. Liu Y, Han L, Bai Y, Du W, Yang B. Down-regulation of MicroRNA-133 predicts poor overall survival and regulates the growth and invasive abilities in glioma. Artif Cells Nanomed Biotechnol 2018; 46: 206-10.

16. Zhang P, Wang J, Lang $\mathrm{H}$, et al. Knockdown of CREB1 promotes apoptosis and decreases estradiol synthesis in mouse granulosa cells. Biomed Pharmacother 2018; 105: 1141-6.

17. Socodato R, Brito R, Portugal CC, de Oliveira NA, Calaza KC, Paes-de-Carvalho R. The nitric oxide-cGKII system relays death and survival signals during embryonic retinal development via AKT-induced CREB1 activation. Cell Death Differ 2014; 21: 915-28.

18. Kim IK, McCutcheon JN, Rao G, et al. Acquired SETD2 mutation and impaired CREB1 activation confer cisplatin resistance in metastatic non-small cell lung cancer. Oncogene 2019; 38: 180-93.

19. Dobroff AS, Wang H, Melnikova VO, et al. Silencing CAMP-response element-binding protein (CREB) identifies CYR61 as a tumor suppressor gene in melanoma. J Biol Chem 2009; 284: 26194-206.

20. Chhabra A, Fernando H, Watkins G, Mansel RE, Jiang WG. Expression of transcription factor CREB1 in human 
breast cancer and its correlation with prognosis. Oncol Rep 2007; 18: 953-8.

21. Wang YW, Chen X, Ma R, Gao P. Understanding the CREB1-miRNA feedback loop in human malignancies. Tumour Biol 2016; 37: 8487-502.

22. Peng B, Hu S, Jun Q, et al. MicroRNA-200b targets CREB1 and suppresses cell growth in human malignant glioma. Mol Cell Biochem 2013; 379: 51-8.

23. Mohamed EA, Kassem HH. Protective effect of nebivolol on doxorubicin-induced cardiotoxicity in rats. Arch Med Sci 2018; 14: 1450-8.

24. Gao L, Li SH, Tian YX, et al. Role of downregulated miR133a-3p expression in bladder cancer: a bioinformatics study. Onco Targets Ther 2017; 10: 3667-83.

25. Huang Y, Wu Y, Dong J, Han D, Yang S, Jiang L. MicroRNA-133a-3p exerts inhibitory effects on gallbladder carcinoma via targeting RBPJ. Am J Cancer Res 2016; 6: 2448-62.

26. Qian J, Li R, Wang YY, et al. MiR-1224-5p acts as a tumor suppressor by targeting CREB1 in malignant gliomas. Mol Cell Biochem 2015; 403: 33-41.

27. Zhang Y, Yang J, Cui X, et al. A novel epigenetic CREBmiR-373 axis mediates ZIP4-induced pancreatic cancer growth. EMBO Mol Med 2013; 5: 1322-34.

28. Evan GI, Vousden KH. Proliferation, cell cycle and apoptosis in cancer. Nature 2001; 411: 342-8.

29. Pandurangan AK, Ismail S, Esa NM, Munusamy MA. Inositol- 6 phosphate inhibits the mTOR pathway and induces autophagy-mediated death in HT-29 colon cancer cells. Arch Med Sci 2018; 14: 1281-8.

30. Luo Z, Pan J, Ding Y, Zhang YS, Zeng Y. The function and clinical relevance of IncRNA UBE2CP3-001 in human gliomas. Arch Med Sci 2018; 14: 1308-20.

31. Rao M, Zhu Y, Cong X, Li Q. Knockdown of CREB1 inhibits tumor growth of human gastric cancer in vitro and in vivo. Oncol Rep 2017; 37: 3361-8.

32. Wang YW, Chen X, Gao JW, et al. High expression of CAMP-responsive element-binding protein 1 (CREB1) is associated with metastasis, tumor stage and poor outcome in gastric cancer. Oncotarget 2015; 6: 10646-57.

33. Snowden AW, Perkins ND. Cell cycle regulation of the transcriptional coactivators $\mathrm{p} 300$ and CREB binding protein. Biochem Pharmacol 1998; 55: 1947-54.

34. Zhang C, Wang L, Wu D, et al. Definition of a FoxA1 cistrome that is crucial for G1 to S-phase cell-cycle transit in castration-resistant prostate cancer. Cancer Res 2011; 71: 6738-48.

35. Wang P, Huang S, Wang F, et al. Cyclic AMP-response element regulated cell cycle arrests in cancer cells. PLoS One 2013; 8: e65661.

36. Pigazzi M, Manara E, Baron E, Basso G. miR-34b targets cyclic AMP-responsive element binding protein in acute myeloid leukemia. Cancer Res 2009; 69: 2471-8. 